\title{
Managing and securing the bleeding upper airway: a narrative review
}

\section{La prise en charge et la protection des voies aériennes supérieures lors de saignements: un compte rendu narratif}

\author{
Michael Seltz Kristensen, MD (1) • Barry McGuire, MD
}

Received: 3 December 2018/Revised: 12 June 2019/Accepted: 14 June 2019/Published online: 23 September 2019

(C) Canadian Anesthesiologists' Society 2019

\begin{abstract}
Failure to manage bleeding in the airway is an important cause of airway-related death. The purpose of this narrative review is to identify techniques and strategies that can be employed when severe bleeding in the upper airway may render traditional airway management (e.g., facemask ventilation, intubation via direct/video laryngoscopy, flexible bronchoscopy) impossible because of impeded vision. An extensive literature search was conducted of bibliographic databases, guidelines, and textbooks using search terms related to airway management and bleeding. We identified techniques that establish a definitive airway, even in cases of impeded visibility resulting from severe bleeding in the airway. These include flexible video-/optical-scope-guided intubation via a supraglottic airway device; cricothyroidotomy or tracheotomy; and retrograde-, blind nasal-, oral-digital-, light-, and ultrasound-guided intubation. We provide a structured approach to managing bleeding in the airway that accounts for the source of bleeding and the estimated risk of failure to intubate using direct laryngoscopy or to achieve a front-ofneck access for surgical airway rescue. In situations where these techniques are predicted to be successful, the recommended approach is to identify the cricothyroid membrane (in preparation for rescue cricothyroidotomy), followed by rapid sequence induction. In situations where traditional management of the airway is likely to fail, we
\end{abstract}

M. S. Kristensen, MD ( $\square)$

Department of Anaesthesia, Centre of Head and Orthopaedics, Rigshospitalet, University Hospital of Copenhagen,

Blegdamsvej 9, 2100 Copenhagen, Denmark

e-mail: Michael.seltz.kristensen@ regionh.dk

B. McGuire, MD

Department of Anaesthesia, Ninewells Hospital and Medical

School, Dundee, UK recommend an awake approach with one of the aforementioned techniques.

Résumé L'échec de la prise en charge des voies aériennes lors de saignements constitue une cause importante de décès lié aux voies aériennes. L'objectif de ce compte rendu narratif était d'identifier les techniques et stratégies qui peuvent être utilisées lorsque des saignements importants localisés dans les voies aériennes supérieures qui rendent la prise en charge des voies aériennes (par ex., ventilation au masque, intubation par laryngoscopie directe ou vidéolaryngoscopie, bronchoscopie) impossible en raison d'une vision obstruée. Une recherche approfondie de la littérature a été effectuée dans les bases de données bibliographiques, les guides d'exercice et les manuels à l'aide de termes de recherche liés à la prise en charge des voies aériennes et au saignement. Nous avons identifié des techniques permettant d'établir des voies aériennes de façon définitive et ce, même en cas de vision obstruée causée par un saignement important dans les voies aériennes. Ces techniques comprennent une intubation guidée par vidéo / optique via un dispositif supraglottique; une cricothyrö̈dotomie ou une trachéotomie; et une intubation rétrograde, nasale en aveugle, orale digitale, échoguidée ou guidée par luminosité. Nous proposons une approche structurée à la prise en charge des voies aériennes lors de saignements qui tient compte de la source du saignement et du risque estimé d'un échec d'intubation par laryngoscopie directe ou pour obtenir un accès via le cou antérieur pour un sauvetage chirurgical des voies aériennes. Dans les situations dans lesquelles on prévoit la réussite de ces techniques, l'approche recommandée est l'identification de la membrane cricothyrö̈dienne (en préparation d'une cricothyroüdotomie de sauvetage), suivie d'une induction en séquence rapide. Dans les situations dans lesquelles une 
prise en charge traditionnelle des voies aériennes va probablement échouer, nous recommandons de tenter une approche éveillée avec une des techniques susmentionnées.

Bleeding in the upper airway is potentially catastrophic, and is an important cause of airway-related death ${ }^{1}$ even in young and otherwise healthy individuals. ${ }^{2}$ The estimated lifetime incidence of epistaxis is approximately $60 \%{ }^{3}$; post-tonsillectomy hemorrhage occurs in $6-15 \%$ of tonsillectomy cases ${ }^{4}$ and bleeding following surgery for malignancy in the upper airway is one of the leading reasons for an emergency surgical airway. ${ }^{5}$ Management of such patients may be extremely challenging because cornerstone techniques commonly employed to secure the airway, such as direct/video laryngoscopy ${ }^{6-8}$ and flexible video/fibreoptic laryngoscopy, ${ }^{9}$ may be ineffective because the hypopharynx - and the equipment—get soiled with blood. Supraglottic airway devices (laryngeal mask type airways) may be employed but are typically of limited efficacy because of the increased risk of aspiration and their potential interference with surgical access to the bleeding site in the hypopharynx, glottis, or trachea. Effective preoxygenation/denitrogenation may not be possible because of poor tolerance to, or function of, a facemask, ${ }^{10}$ or high flow nasal oxygenation cannula. ${ }^{11,12}$ The clinician is thus forced to use other techniques and modify the approach to airway management especially if the pre-induction airway examination reveals that direct laryngoscopy (DL) and/or rescue cricothyroidotomy are likely to fail. We have been faced with managing the difficult bleeding airway on numerous occasions, but have so far not come across a comprehensive review of the options for safe management of these cases. Hence, we have attempted to fill the gap with this narrative review.

\section{Methods}

This narrative review is based on the following sources for the management of the bleeding upper airway: a search of the literature databases including PubMed, Embase, Scopus, CINAHL, Cochrane Central Register of controlled trials, and Cochrane database of systematic reviews, using search terms combining airway, airway management, bleeding, and hemorrhage, and guidelines for management of the difficult airway ${ }^{13-16}$ and relevant textbooks. ${ }^{17-23}$ Additionally, references cited in the retrieved literature were scrutinized for relevance. The titles/abstracts were evaluated and the full text retrieved from relevant articles (Fig. 1). All searches were limited to humans and only references from peer-reviewed journals were included in the database search. The literature search concluded February 2019.

\section{Results}

The literature search (Fig. 1) retrieved 97 references (15 case series, 23 cases, nine prospective observational studies, eight randomized studies, three controlled nonrandomized studies, three systematic and 11 nonsystematic reviews, 13 text books/book chapters, four editorials, four guidelines, two letters, one technical paper, and one webpage) that were included in this narrative review.

\section{Etiology and characteristics of a bleeding airway}

Airway bleeding is an actual or potential emergency, depending on the site and severity of the bleeding and the physiological compromise of the patient; these factors will influence the subsequent medical management. Airway assessment is focused on how to safely secure the airway and control (or stop) the bleeding. An emphasis on oxygenation, organization of personnel, and preparation of the equipment and environment, as stressed in airway guidelines, is essential. The potential causes of bleeding in the upper airway are summarized in Table 1 and the characteristics that make management so challenging are listed in Table 2.

\section{Initial management}

Key points include limiting the bleeding ${ }^{24}$; giving oxygen $^{10}$; initiating fluid/blood resuscitation ${ }^{25}$; and correcting any underlying coagulopathy. ${ }^{26}$ It is wise to assume that the amount of blood visible externally represents only a fraction of what may be encountered on initiation of airway management. Simple measures are crucial-including reassurance of the patient and maintenance of an upright posture.

\section{Limiting the bleeding}

If possible, it is always preferable to reduce or stop the bleeding before securing the airway. This may make subsequent airway management easier or even unnecessary. In post-tonsillectomy/adenoidectomy ${ }^{24}$ or other oral/pharyngeal bleeding scenarios, trans-oral compression of the bleeding vessel can be performed with a clamped swab or an index finger. Timely embolization of the sublingual artery to treat bleeding associated with dental surgery has been described ${ }^{27}$ and 


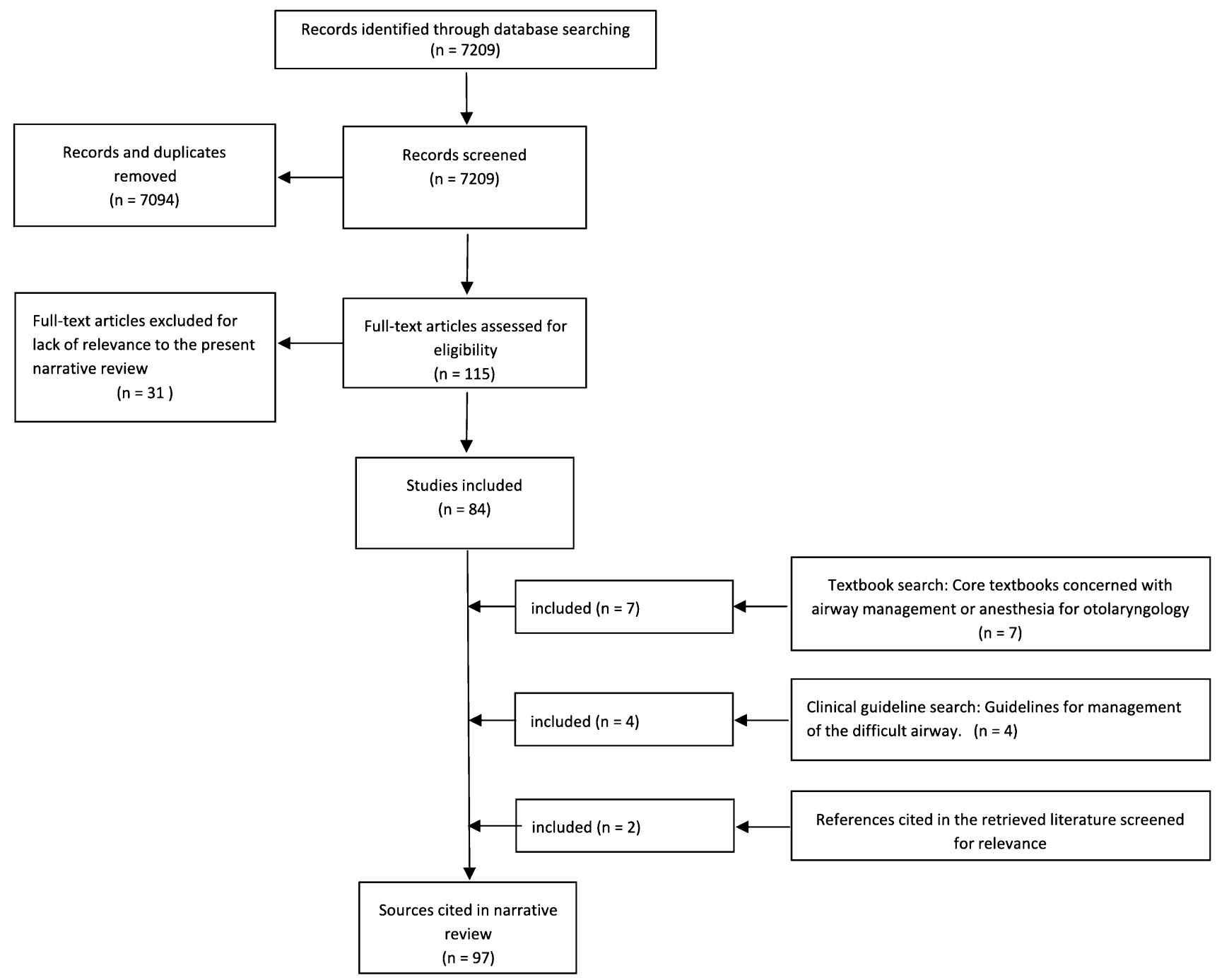

Fig. 1 Flow diagram showing the sources that were searched for literature about the management of bleeding in the upper airway

Table 1 Etiology of upper airway bleeding that can make airway management challenging

\begin{tabular}{|c|c|}
\hline Condition & Examples \\
\hline Spontaneous/idiopathic & Nasal bleeding ${ }^{70}$ \\
\hline Bleeding tumour/malignancy $5 /$ vascular malformation ${ }^{71}$ & Oral, nasal, pharyngeal, laryngeal locations \\
\hline $\begin{array}{l}\text { Coagulopathy, }{ }^{26,72} \text { anticoagulation treatment or thrombolytic } \\
\text { therapy }\end{array}$ & Pharyngeal bleeding following thrombolytic therapy ${ }^{73}$ \\
\hline Trauma to the face or neck ${ }^{10,44}$ & Maxillofacial, neck, and laryngeal injury ${ }^{10}$ \\
\hline Post-surgery ${ }^{5,24,74}$ & $\begin{array}{l}\text { E.g., post-tonsillectomy, post cancer surgery, }{ }^{5} \text { and following dental implant } \\
\text { insertion }{ }^{74}\end{array}$ \\
\hline Iatrogenic-often due to airway management & Oral $^{75}$ or nasal ${ }^{76}$ intubation, application of facemask (facial trauma) ${ }^{77}$ \\
\hline Cocaine abuse & Nasal or alveolar bleeding ${ }^{78}$ \\
\hline
\end{tabular}

epistaxis can be treated with intranasal packs. $^{28}$ Soaking the swab with a topical haemostatic agent, such as epinephrine or thrombin may help control bleeding. Anti- fibrinolytics, such as tranexamic acid, ${ }^{29}$ should also be considered and, in addition to intravenous injection, may be administered via nebulization ${ }^{30}$ or applied directly with 
Table 2 Summary of challenges posed by upper airway bleeding

Reason Comment

All techniques used to manage these scenarios are likely to be difficult Effective multidisciplinary strategy planning involving mobilization of and may fail

Altered functionality of airway management devices available resources ${ }^{79}$ and experienced staff is essential.

Video laryngoscopes ${ }^{6-8}$ and flexible optical-/video-scopes ("fibrescopes") 9 may be ineffective in the bleeding airway, even in experienced hands. ${ }^{80}$

Supraglottic airway devices are not suitable as definitive airways

Risk of aspiration of blood from the stomach ${ }^{1}$; interference with surgical access.

Preoxygenation and denitrogenation are less efficient

Patient may already be hypoxic and agitated. ${ }^{32}$ Often difficult to apply a tight-fitting facemask with a good seal; worsening airway obstruction, may contribute to subcutaneous emphysema. ${ }^{10}$

High flow nasal oxygenation (HFNO) may fail; ${ }^{11}$ transnasal humidified Blood in the airway is a potential cause of interrupted gas flow and insufflation ventilatory exchange (THRIVE) is not recommended ${ }^{12}$

Requires urgent or emergent hemostasis ${ }^{81}$ blood may be forced into the distal airway. ${ }^{11}$

Obstructed vision $^{82}$

Concomitant suctioning ${ }^{81}$

A blood clot can mimic tissue/pathology ${ }^{83}$

A blood clot can obstruct or displace ${ }^{82}$ the airway

The patient often cannot lie flat ${ }^{43}$

Hypovolemia with impending or established circulatory collapse $\mathrm{e}^{29}$

Aspiration risk due to blood in the upper airway or stomach ${ }^{68}$

May require emergency front-of-neck-access $5,82,84$

Bleeding management can rarely be postponed to the following day.

Blood can render any device that relies on visualization (including direct laryngoscopy) impossible. ${ }^{81}$

Suctioning of upper airway with two suctioning systems enhances view $^{46}$ but limits working space and adds complexity to medical care.

'Waking up the patient' following failed airway management is rarely an option

The patient may re-bleed upon extubation ${ }^{62}$

Re-bleeding can occur between seconds ${ }^{62}$ and weeks ${ }^{86}$ after extubation.

Clinical care team overwhelmed by stress

Training to manage these cases requires non-technical skills education. $^{79}$

drug-soaked cotton pledgets ${ }^{31}$ for uncontrolled airway bleeding.

\section{Oxygenation}

Proactive oxygenation ${ }^{10}$ throughout airway management is a cornerstone of safe patient care. Whenever possible, binasal oxygen delivery prior to, and during, intubation is beneficial. This should be supplemented by facemaskdelivered oxygen if possible, although this may not be tolerated by patients with active airway bleeding, and is relatively contraindicated in facial trauma, particularly skull base fractures where it increases the risk of intracranial infection. ${ }^{10}$ High Flow Nasal Oxygen (HFNO)/Transnasal Humidified Rapid-Insufflation Ventilatory Exchange (THRIVE) should be used with extreme caution when there is bleeding ${ }^{12}$ and is relatively contraindicated $^{12}$ as blood may be forced distally into the trachea. Moderate flow rates $\left(8-20 \mathrm{~L} \cdot \mathrm{min}^{-1}\right)$ may be better than high flow rates. Cautious sedation with ketamine may be necessary to facilitate effective preoxygenation/ denitrogenation in the uncooperative patient. ${ }^{32}$

Fluid/blood resuscitation and correction

of coagulopathy

With severe bleeding, the patient may be hypovolemic ${ }^{30}$ and in such cases large-bore intravenous access and crystalloid/colloid/blood resuscitation should be initiated. Blood samples should be sent expeditiously for cross match. Volume replacement is the cornerstone of resuscitation for profuse bleeding, but non-targeted aggressive fluid resuscitation must be avoided to allow clot formation and to prevent increased bleeding. ${ }^{25}$ If faced with a coagulopathy, this needs to be actively managed ${ }^{26}$ and expert hematology input may be sought if time permits. Maintenance of normothermia (including warming of administered fluids) and correction of 
metabolic acidosis are important considerations, as with any massive transfusion scenario.

\section{Airway management}

Bleeding in the upper airway (above the vocal cords) is a relatively common scenario. ${ }^{3,4}$ Of the many possible ways of managing the airway, only placement of a cuffed tube in the trachea fulfils the desired goals of a) securing a conduit for patient ventilation, b) protecting against further aspiration of blood into the lungs, and c) allowing sufficient access to surgically address the source of bleeding.

A cuffed endotracheal tube can be inserted via the oral or nasal route, cricothyroid membrane (CTM), or tracheal stoma. The choice will be influenced by the site of bleeding and the approach required for safe airway management. Supraglottic airway devices, such as the laryngeal mask airway or the Combitube (Tyco Healthcare Group LP, Boulder, CO, USA), should only be considered as a temporary means of securing the airway, as they do not definitively isolate the lungs from blood in the upper airway. To guard against aspiration, it is preferable to insert a cuffed endotracheal tube either following rapid sequence induction (RSI) or while the patient is awake. An RSI should only be performed if the pre-anesthetic airway evaluation does not suggest difficulty with DL and confirms that the CTM is identifiable, and thus accessible should DL fail. A stepwise approach to managing the bleeding upper airway is summarized in Fig. 2.

\section{Airway evaluation}

Despite the limitations in predicting difficult/failed DL, a thorough preoperative airway evaluation is essential to help inform whether an awake technique, rather than an RSI, would be a safer approach. The evaluation can be done at the bedside. Features suggestive of a potentially difficult DL include limited mouth opening, mandibular protrusion, thyromental distance, submandibular compliance, sternomental distance or head and upper neck extension, Mallampati class 3 or 4 , narrow dental arch, increased neck circumference, and history of previous difficult airway management. ${ }^{14,33-35}$ Nevertheless, even with a reassuring airway assessment that suggests easy DL, this evaluation will occasionally mislead and therefore preparation must also include provision for a front-of-neck access (FONA) like a cricothyroidotomy or tracheotomy.

A difficult FONA is more likely in cases of female sex, age < eight years, thick/obese neck, overlying pathology (inflammation, induration, radiation, tumour), a displaced airway, or a fixed cervical spine flexion deformity. ${ }^{14}$

\section{Identification of the CTM}

The potential need for a FONA, either pre-emptively or as part of airway rescue, is substantial when managing the bleeding airway. In small children ( $<$ ten years old) tracheotomy may be the preferred FONA approach ${ }^{36}$ but the ideal approach depends on skill and experience. ${ }^{37}$ In adults, a scalpel cricothyroidotomy is the FONA technique of choice to rescue a "can't intubate, can't oxygenate" scenario according to recent guidelines. ${ }^{15}$ For elective FONA in the awake patient there is less time pressure than in the emergent situation, and thus either a cricothyroidotomy or a tracheotomy may be performed. While the patient is being stabilized and prepared for definitive airway management, (ideally prior to induction of general anesthesia, circumstances permitting) the CTM and trachea should be identified and marked. ${ }^{38}$ Ideally, this should be done in conjunction with a surgical colleague skilled in upper airway surgery. In slim individuals, inspection and palpation will usually identify the CTM and trachea. ${ }^{39}$ However, both conventional palpation and the "laryngeal handshake" 40 technique have a high failure rate of identification in obese patients and in patients with neck pathology. In such cases, the CTM and trachea may be identified quickly and reliably using ultrasonography. ${ }^{39,41}$ Accurate identification of the CTM and trachea facilitates both pre-emptive and rescue cricothyroidotomy, tracheotomy, and awake retrograde intubation. ${ }^{42}$ The CTM should ideally be marked with the patient's head in the same position that the clinician would potentially use for surgical access via the CTM. If the CTM is identified and marked in the sitting position, its location might change when the patient is placed supine. We emphasize that ultrasonography for correct identification of the CTM and trachea may be life-saving. ${ }^{42}$

\section{Rapid sequence induction}

If the airway evaluation reassures that intubation under DL is likely to be successful, and that the CTM and the trachea are identifiable, then an RSI is indicated. The patient may be hypovolemic ${ }^{29}$ and in such cases large-bore intravenous access and fluid/blood resuscitation should be initiated. A continuously cycling non-invasive blood pressure cuff, or invasive blood pressure monitoring (time and circumstances permitting) will help to monitor and treat hypotension that typically accompanies induction of general anesthesia. Ready access to vasopressors such as ephedrine and phenylephrine must be ensured, and judicious use of appropriate (small) doses of hypnotics and opioids may be necessary to avoid catastrophic cardiovascular collapse. Induction with ketamine or etomidate should be considered. The patient often needs 


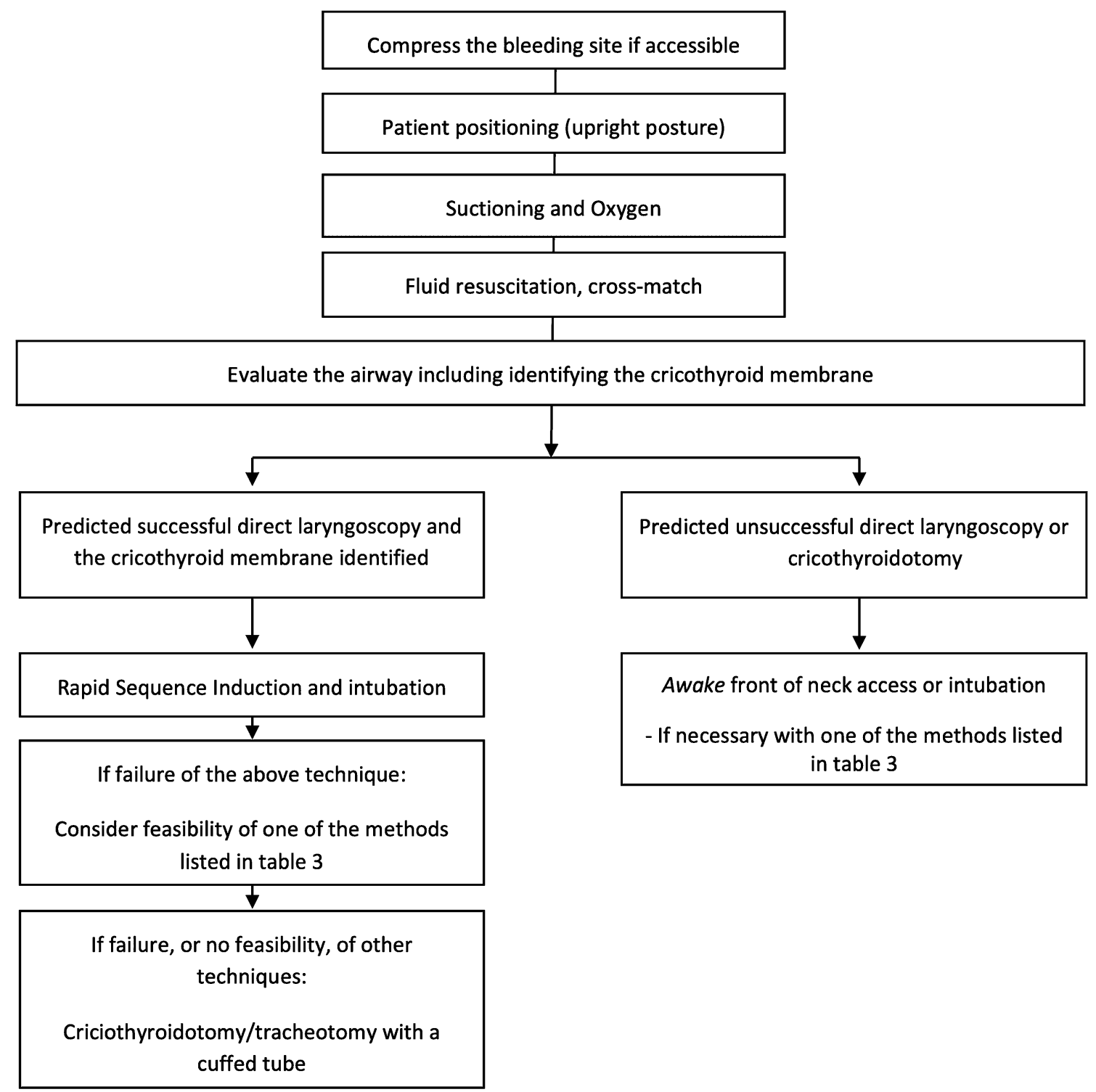

Fig. 2 Flow chart summarizing approach to managing the bleeding upper airway. Please refer to the main text for detailed explanation

to be sitting, ${ }^{43}$ or even leaning forward, until unconsciousness is achieved and can subsequently be placed in a sniffing, semi-lateral, or head down position depending on preference and circumstances. An assistant solely dedicated to managing hemodynamic changes and fluid resuscitation may be necessary.

Two direct laryngoscopes should be available in case one fails and ideally one of these should be a video laryngoscope with a Macintosh-shaped blade; it can be used as a direct laryngoscope if blood obscures the video function of the device or as a video laryngoscope if blood soiling is less than expected and the direct view is more restricted than predicted.

Two rigid, large-bore Yankauer-type suction catheters ${ }^{44}$ attached to separate suction sources should be available, as well as Magill forceps to retrieve clots in the oropharynx. ${ }^{45}$ An assistant dedicated to suctioning of the airway may be required. When optimal glottic visualization is obtained, the suction catheter can be wedged to the left side of the laryngoscope, ${ }^{44}$ in the upper oesophagus, ${ }^{46}$ or in the hypopharynx below the glottis to prevent re-flooding of the airway during intubation. A malleable intubation guide/ bougie/introducer may be useful if the larynx is partially covered with blood, as visibility of the epiglottis, not the larynx, may be sufficient to effectively insert these devices. Some authors even categorise the use of such guides as a "nonvisual" techniques ${ }^{47}$ despite some visualization being required to identify the epiglottis.

Following intubation, it is advisable to suction down the tracheal tube prior to commencing assisted ventilation. 
This will limit blood contamination of the distal airways; otherwise, distal airway obstruction may occur because of blood and/or clot.

Approach if the airway examination suggests DL may fail

The approaches recommended in airway management algorithms $^{7-10}$ almost exclusively depend on visualization of the glottis (directly or indirect, Table 2) and so are inadequate when employed in the bleeding airway, particularly when the bleeding is profuse. Table 3 summarizes methods for securing the airway that are less affected by the presence of blood. These include flexible video/optical endoscope-guided intubation via a supraglottic airway device, retrograde intubation, blind oral and blind nasal intubation, light-guided intubation, ultrasound-guided intubation, cricothyroidotomy, and tracheotomy. Finally, cardiopulmonary bypass or extracorporeal membrane oxygenation may be employed for bridging in desperate situations.

These methods may be employed in an awake patient when techniques to visualize the glottis (typically flexible or rigid video laryngoscopy) have failed or are anticipated to fail. These methods may also be considered in the unconscious/anesthetized patient, if clinically appropriate, when visualization-dependent techniques have failed because of excessive bleeding. Otherwise, FONA will be the technique of choice.

\section{Awake approach}

An awake approach to securing the airway is prudent especially if the airway assessment suggests that intubation after induction of general anesthesia may fail and/or that the "rescue technique", usually cricothyrotomy, may be

Table 3 Airway techniques that do not rely on visualization of the glottis, and may be considered when the upper airway is soiled with blood

\begin{tabular}{|c|c|c|}
\hline Technique & Indication & Comments \\
\hline Supraglottic airway devices ${ }^{52,53}$ & $\begin{array}{l}\text { For failed ventilation and/or as a conduit } \\
\text { for intubation, }{ }^{53} \text { in the awake }{ }^{52} \text { or } \\
\text { unconscious patient. }\end{array}$ & $\begin{array}{l}\text { Only suitable for bleeding above the larynx. Requires } \\
\text { adequate mouth opening. Poor protection against } \\
\text { aspiration. Mainly temporizing technique until intubation } \\
\text { is achieved. }\end{array}$ \\
\hline Retrograde intubation ${ }^{42,50,66,87,88}$ & $\begin{array}{l}\text { An awake approach is recommended, but } \\
\text { can be applied in the unconscious } \\
\text { patient. }\end{array}$ & $\begin{array}{l}\text { May be used in patients with critical cervical spine lesions. } \\
\text { Can be applied with a supraglottic airway device in } \\
\text { place. }{ }^{59} \text { Can be combined with light-guided intubation. }{ }^{67}\end{array}$ \\
\hline $\begin{array}{l}\text { Light-guided intubation, using either } \\
\text { a lightwand, }{ }^{49} \text { or a flexible endo } \\
\text { scope }^{48} \text { as light-guide }\end{array}$ & $\begin{array}{l}\text { Awake, following induction, or } \\
\text { unconscious. }\end{array}$ & $\begin{array}{l}\text { High success rate in predicted difficult intubation in } \\
\text { spontaneous breathing, }{ }^{90,91} \text { or anesthetized }{ }^{91} \text { patients. Can } \\
\text { be combined with retrograde intubation. }{ }^{67}\end{array}$ \\
\hline Blind nasal intubation ${ }^{90,92}$ & $\begin{array}{l}\text { Must be guided by breath sounds. } \\
\text { Awake or with preserved spontaneous } \\
\text { bleeding. }\end{array}$ & $\begin{array}{l}\text { High success rate in spontaneous breathing patients with neck } \\
\text { trauma. }{ }^{92}\end{array}$ \\
\hline Cricothyroidotomy ${ }^{60}$ & $\begin{array}{l}\text { Pre-emptive }{ }^{60} \text { or rescue. }^{5} \\
\text { Awake, following induction, or } \\
\text { unconscious. }\end{array}$ & $\begin{array}{l}\text { Patient may be unable to lie flat (but semi-recumbent position } \\
\text { may be an option). }\end{array}$ \\
\hline Tracheotomy & $\begin{array}{l}\text { Pre-emptive }{ }^{63} \text { or rescue. } \\
\text { Awake, }{ }^{63} \text { following induction, }{ }^{5} \text { or } \\
\text { unconscious. }\end{array}$ & \\
\hline $\begin{array}{l}\text { Ultrasound-guided } \\
\text { intubation } 93,94\end{array}$ & $\begin{array}{l}\text { Visualization obscured by blood. }{ }^{93} \\
\text { Awake, following induction, or } \\
\text { unconscious }\end{array}$ & $\begin{array}{l}\text { Requires separate operator. Recommended for the bleeding } \\
\text { airway, but only limited clinical use reported in the } \\
\text { literature }\end{array}$ \\
\hline Oral-digital intubation ${ }^{47}$ & $\begin{array}{l}\text { Difficult technique; demands adequate } \\
\text { mouth opening. }\end{array}$ & Rarely tolerable for the awake patient. ${ }^{47}$ \\
\hline $\begin{array}{l}\text { Esophageal Combitube, }{ }^{73,95} \\
\quad \text { Laryngeal tube, or similar device }\end{array}$ & Mainly as rescue technique. & $\begin{array}{l}\text { Bulky; may be traumatic to insert; may interfere with surgical } \\
\text { access. }\end{array}$ \\
\hline $\begin{array}{l}\text { Cardiopulmonary bypass/extra } \\
\text { corporeal membrane } \\
\text { oxygenation }^{96,97}\end{array}$ & $\begin{array}{l}\text { Has been used for massive hemoptysis }{ }^{96} \\
\text { and tracheal granuloma. }{ }^{97}\end{array}$ & $\begin{array}{l}\text { Does not protect from aspiration; may not be available for } \\
\text { emergency use; anticoagulation requirement may } \\
\text { complicate hemostasis. }\end{array}$ \\
\hline
\end{tabular}

Significant bleeding airway scenarios are challenging to manage and may necessitate the use of techniques less familiar to the treating physician. Patient management should be performed by individuals who have experience with these techniques and have rehearsed the bleeding airway scenario 
difficult or impossible. ${ }^{14}$ The awake approach can be either via tracheal intubation or FONA. A sitting position and applying pressure to the bleeding site with gauze-loaded forceps may be helpful. If the bleeding is limited, then awake flexible endoscopy or awake videolaryngoscopy can be attempted, but the operator must be prepared for failure.

If airway visualization with the flexible endoscope or video laryngoscope is unsuccessful, an alternative awake technique is required (Table 3). Occasionally, unsuccessful awake intubation can be salvaged using a flexible endoscope as a "lighted stylet". The tip of the endoscope is advanced posteriorly past the epiglottis and caudal towards the estimated position of the glottic opening and then the tip of the scope is manipulated anteriorly to wedge it against the anterior luminal surface of the trachea. The light from the scope can then be seen through the anterior neck, thus verifying the position of the tip of the scope in the trachea. ${ }^{48}$ If clinicians wish to include such a technique in their airway management armamentarium, then it should be practiced in the non-bleeding airway to optimize its familiarity.

\section{Airway topicalization and sedation}

Airway topicalization (e.g., nebulized, atomized, gauze/pledget soaked with local anesthetic) is largely ineffective in the presence of blood and alternative methods may be required. Bilateral superior laryngeal nerve blocks combined with trans-tracheal injection of local anesthetic may produce a superior result. ${ }^{49}$ Nevertheless, it may be preferable to refrain from anesthetizing the trachea so that the patient can still react (cough) if blood enters the trachea; the trade-off is that the patient may also react when the endotracheal tube enters the trachea, but this does not seem to limit the success of intubation. In fact, the presence of blood lubricates the airway so that intubation may be possible without local anesthetic and with only limited patient discomfort. ${ }^{50}$ In patients presenting with severe respiratory distress or with hypercarbia-induced somnolence, and a likely difficult DL, awake intubation with an appropriate technique is indicated and is often well tolerated without topicalization or sedation. ${ }^{51}$ Nevertheless, in some patients, cautious sedation may be required; ketamine may be particularly helpful as there is little associated respiratory depression. ${ }^{32}$

Ventilation and intubation via a supraglottic airway device

A supraglottic airway device can protect the trachea to some degree from blood soiling, provided that the origin of the bleeding is above the glottis. This can permit life- saving ventilation. The insertion of a supraglottic airway device and using it as a conduit for intubation can be applied in the awake patient, ${ }^{52}$ or used as a rescue technique in the unconscious (or anesthetized) patient after failed intubation ${ }^{53}$ or facemask ventilation. ${ }^{54} \mathrm{~A}$ supraglottic airway device (without subsequent intubation) should be used with caution and should be considered only as a temporary solution as it offers limited protection from aspiration. Of note, a supraglottic airway may not provide sufficient space for surgical access to the bleeding site.

A supraglottic airway device specifically designed to accommodate an endotracheal tube should be used, and the intubation should be performed under visual guidance of a flexible endoscope. If a standard supraglottic airway device (i.e., not designed to facilitate intubation) is used, successful intubation can be facilitated using an Aintree Intubation Catheter (Cook Medical, Bloomington, IN, USA) with an appropriately sized fibrescope and endotracheal tube. ${ }^{13} \mathrm{~A}$ second-generation supraglottic airway device with large-bore gastric access may allow egress or suctioning of blood from the stomach, but may not provide effective protection against aspiration. "Blind" (i.e., without guidance of a flexible, optical endoscope) intubation via a supraglottic airway device in a bleeding airway has been described, ${ }^{53}$ and may be considered as a last resort prior to emergency FONA. ${ }^{55}$ Nevertheless, we would caution that blind techniques have an unacceptably low success rate, ${ }^{56}$ especially in children ${ }^{57}$; flexible, optical endoscope-guided intubation has a higher success rate ${ }^{58}$ and should be used whenever possible. Finally, supraglottic airway device ventilation can be converted to endotracheal tube ventilation using a retrograde technique; a guidewire is passed via the CTM, directed cranially via the supraglottic airway device, and then used to guide an obturator anterogradely via the proximal end of the device and then out through the distal end, which in turn can be used to guide insertion of an endotracheal tube. ${ }^{59}$

\section{Cricothyroidotomy}

Cricothyroidotomy can be performed in the awake patient as a primary or "pre-emptive" airway, ${ }^{60}$ or after induction as an airway rescue for failed intubation. ${ }^{5}$ In adults, it should be performed using a technique that permits the placement of a cuffed endotracheal tube of at least a $5-\mathrm{mm}$ internal diameter. This will provide effective ventilation while protecting against further aspiration, ${ }^{61}$ yet allow sufficient space for surgical treatment of bleeding. A narrow-bore cannula ("needle") cricothyroidotomy is not suitable other than as a temporary oxygenation technique. ${ }^{62}$ 


\section{Tracheotomy}

Similarly, tracheotomy can be used as a primary, awake approach $^{63}$ or as a rescue technique ${ }^{5}$ and is the FONA technique of choice in smaller children ( $<$ ten years). ${ }^{36}$ In a child with a bleeding airway, it is crucial to have a gloved surgeon present during induction of anesthesia as immediate tracheotomy may be necessary because of intubation failure. ${ }^{24}$

\section{Profuse bleeding}

If the bleeding is so profuse that flexible or rigid videolaryngoscopy are likely to (or have) fail(ed), then a variety of options may be considered (Table 3). Awake, pre-emptive tracheotomy ${ }^{63}$ or cricothyroidotomy ${ }^{60}$ should always be considered in such cases. Nevertheless, in certain scenarios, other awake approaches may be preferable depending on clinical experience. Of these, the retrograde "pulling" technique is especially well-suited in the management of an awake, sitting patient with a profusely bleeding airway. Retrograde intubation, where the tube is pulled either through the nose or mouth into the trachea using an epidural catheter inserted through the CTM, or through the crico-tracheal membrane, ${ }^{64}$ has the following advantages: it is relatively simple, requires readily available equipment (an epidural catheter), ${ }^{47}$ is independent of vision and thus works in bloody airways, ${ }^{42}$ allows intubation via the mouth or the nose as appropriate, $^{65}$ and allows re-intubation if necessary (as the catheter is left in situ following extubation). The technique should preferably be used in the awake patient. One detailed approach to this technique has been described. ${ }^{50}$ The CTM or the crico-tracheal membrane is identified and an $18 \mathrm{G}$ venous cannula is introduced into the airway through which an epidural catheter is introduced in a cephalad direction until it protrudes via the mouth. Subsequently the epidural catheter is looped around the Murphy eye so the tube can be pulled into the trachea using a "sliding knot". 50 If a nasal intubation is preferable, a second epidural catheter can be inserted through the nares, and "fished" out of the mouth using forceps. This catheter can be tied to the catheter inserted via the CTM (above), and pulled cephalad until there is a single, unknotted length of epidural catheter extending from the nares to CTM. The epidural catheter can then be looped through the Murphy eye of the endotracheal tube, and used to guide it into the trachea. ${ }^{65}$

Alternative retrograde intubation techniques for the bleeding difficult airway include a long guidewire and a tube-exchange catheter, $^{42}$ a Tuohy needle and a guidewire, ${ }^{66}$ retrograde intubation with a supraglottic airway device in place, ${ }^{59}$ or a dedicated kit specifically designed for this purpose. ${ }^{47}$

Finally, lightwand-guided intubation is another useful technique in this setting and can even be used in combination with retrograde intubation. ${ }^{67}$ This approach requires dedicated equipment, although a flexible endoscope may be used for this purpose, ${ }^{48}$ as briefly described above.

The unconscious patient

In the unconscious patient with an urgent need for a cuffed endotracheal tube, typically a major trauma patient, the choices for airway management are the same as those listed in Fig. 2 and Table 3, without the "awake" options. Nevertheless, if the patient has sufficient spontaneous ventilation these techniques may still be attempted. The initial approach would most often be an attempt at intubation with DL followed by FONA in case of failure, or alternatively with FONA as the primary approach.

\section{Postoperative management}

If there is suspicion of aspiration of blood from the upper airway into the tracheobronchial tree, this should be verified and appropriately treated by suctioning via a flexible optical endoscope. ${ }^{68}$ Multidisciplinary discussion and planning are needed to manage postoperative care. Consideration should be given to keeping the patient intubated in a high acuity recovery area (e.g., intensive care unit) until the cessation of bleeding is certain, fluid status has been appropriately managed, and any coagulopathy has been addressed. The treating team must formulate an airway rescue plan to deal with the possibility of recurring bleeding or the airway becoming compromised following extubation. Corticosteroid therapy should be initiated in case of expected postoperative stridor. ${ }^{69}$

\section{Caveats}

Owing to the limited data that are available, it is not possible to provide a systematic review, making it difficult to provide definitive conclusions on how to best manage various bleeding airway scenarios. It is hard to imagine how to design comparative prospective studies that could account for the complex clinical presentation of these patients, with etiologies ranging from medical (coagulopathy) to trauma to malignancy. The options we review have various advantages and disadvantages, and the choice for any one technique relates to the clinical 
circumstances, available equipment and-most importantly-clinical experience. It is crucial to gain familiarity with these techniques in the non-urgent situation, and we would strongly encourage healthcare providers who may handle this type of challenging patient to participate in workshops towards this end.

\section{Conclusion}

The bleeding upper airway can be extremely challenging to manage, and requires a structured, multidisciplinary approach to achieve a successful outcome. Optimization of both technical and non-technical (i.e., communication, organization, and teamwork) skills is crucial. Standard airway management algorithms based on being able to visualize the glottis directly or indirectly, may be inadequate in this scenario.

The situation is made all the more challenging by the tremendous pressure to provide expeditious, expert medical care. Presentation, audit, and review of such cases are important so lessons can be learned and future management improved. Undoubtedly, there will be clinicians facing such scenarios for the first time and our hope is that this review will make that experience less daunting.

Acknowledgements Michael Friis Tvede, consultant anaesthetist, Department of Anaesthesia, Centre of Head and Orthopaedics, Rigshospitalet, University Hospital of Copenhagen, Denmark, is thanked for sparring and for uploading and maintaining the illustrations, video, and video links to the website http:// airwaymanagement.dk. Søren Steemann Rudolph, consultant anaesthetist, Department of Anaesthesia, Centre of Head and Orthopaedics, Rigshospitalet, University Hospital of Copenhagen, Denmark, is thanked for critical reading of the manuscript

Declaration of interests Michael Seltz Kristensen has been an unpaid member of the advisory board of AMBU A/S, Denmark. He has no economic interests related to the present study. He is currently the President of European Airway Management Society (EAMS) (www.eamshq.net). This paper represents his personal views and is not written under the auspices of EAMS. Barry McGuire is President of the Difficult Airway Society (DAS), UK. This paper represents his personal views and is not written under the auspices of DAS.

Editorial responsibility This submission was handled by Dr. Steven Backman, Associate Editor, Canadian Journal of Anesthesia.

Author contributions Michael Seltz Kristensen initiated the study, undertook the initial literature search, wrote the initial draft of the manuscript, obtained the right to use the illustrations, and critically revised all subsequent versions of the manuscript. Barry McGuire contributed to the planning of the study, added supplementary literature, added to the initial draft of the manuscript, and critically revised all subsequent versions of the manuscript.

Funding No funding was received for this study.

\section{References}

1. Cook T, Frerk C. Chapter 19 Aspiration of gastric contents and of blood. In: Cook T, Woodall N, Frerk C, editors. 4th National Audit Project (NAP4). London: The Royal College of Anaesthetists; 2011. p. 155-64.

2. Windfuhr JP, Schloendorff G, Baburi D, Kremer B. Serious posttonsillectomy hemorrhage with and without lethal outcome in children and adolescents. Int J Pediatr Otorhinolaryngol 2008; 72: 1029-40.

3. Gifford TO, Orlandi RR. Epistaxis. Otolaryngol Clin North Am 2008; 41: 525-36, viii.

4. Odhagen E, Sunnergren O, Soderman AH, Thor J, Stalfors J. Reducing post-tonsillectomy haemorrhage rates through a quality improvement project using a Swedish National quality register: a case study. Eur Arch Otorhinolaryngol 2018; 275: 1631-9.

5. Darby JM, Halenda G, Chou C, Quinlan JJ, Alarcon LH, Simmons $R L$. Emergency surgical airways following activation of a difficult airway management team in hospitalized critically ill patients: a case series. J Intensive Care Med 2018; 33: 517-26.

6. Syed M, Irby $J$. Airway management of ruptured pulmonary artery "Rasmussen" aneurysm and massive hemoptysis. BMC Res Notes 2015; DOI: https://doi.org/10.1186/s13104-015-1313-

7. Zhong T, Yuan JQ, Story DA. Airway management in adults with bleeding airways. Anaesth Intensive Care 2011; 39: 140.

8. Joshi R, Hypes $C D$, Greenberg $J$, et al. Difficult airway characteristics associated with first-attempt failure at intubation using video laryngoscopy in the intensive care unit. Ann Am Thorac Soc 2017; 14: 368-75.

9. Yumoto T, Matsumura T, Tsukahara K, Sato K, Ugawa T, Ujike Y. A case of cricothyroidotomy for facial trauma in a patient taking antiplatelet agents after a simple ground-level fall. Int J Surg Case Rep 2016; 27: 87-9.

10. Jain U, McCunn M, Smith CE, Pittet JF. Management of the traumatized airway. Anesthesiology 2016; 124: 199-206.

11. Rummens N, Ball DR. Failure to THRIVE. Anaesthesia 2015; 70 : 752-3.

12. Yang $\mathrm{SH}, \mathrm{Wu} \mathrm{CY}$, Tseng WH, et al. Nonintubated laryngomicrosurgery with Transnasal humidified rapidinsufflation ventilatory exchange: a case series. J Formos Med Assoc 2018; 118: 1138-43.

13. Law JA, Broemling N, Cooper RM, et al. The difficult airway with recommendations for management-part 1-difficult tracheal intubation encountered in an unconscious/induced patient. Can J Anesth 2013; 60: 1089-118.

14. Law JA, Broemling N, Cooper RM, et al. The difficult airway with recommendations for management-part 2-the anticipated difficult airway. Can J Anesth 2013; 60: 1119-38.

15. Frerk C, Mitchell VS, McNarry AF, et al. Difficult Airway Society 2015 guidelines for management of unanticipated difficult intubation in adults. Br J Anaesth 2015; 115: 827-48.

16. Apfelbaum JL, Hagberg CA, Caplan RA, et al. Practice guidelines for management of the difficult airway: an updated report by the American Society of Anesthesiologists Task Force on Management of the Difficult Airway. Anesthesiology 2013; 118: 251-70.

17. Hagberg CA, Artime CA, Aziz MF. Hagberg and Benumof's airway management. 4th ed. Philadelphia: Elsevier; 2018 .

18. Berkow LC, Sakles JC. Cases in Emergency Airway Management. 1st ed. Cambridge: Cambridge University Press; 2015 .

19. Calder I, Pearce A. Core Topics in Airway Management. 2nd ed. Cambridge: Cambridge University Press; 2011. 
20. Doyle DJ, Abdelmalak B. Clinical Airway Management - An Illustrated Case-Based Approach. 1st ed. Cambridge: Cambridge University Press; 2017.

21. Rosenblatt WH, Popescu WM. Master Techniques in Upper and Lower Airway Management. 1st ed. Philadelphia: Wolters Kluwer Health; 2015.

22. Hung OR, Murphy MF. Hung's Difficult and Failed Airway Management. 3rd ed. New York: McGraw-Hill Education; 2018.

23. Abdelmalak B, Doyle DJ. Anesthesia for Otolaryngologic Surgery. 1st ed. Cambridge: Cambridge University Press; 2013.

24. Windfuhr JP, Schloendorff $G$, Sesterhenn AM, Prescher A, Kremer B. A devastating outcome after adenoidectomy and tonsillectomy: ideas for improved prevention and management. Otolaryngol Head Neck Surg 2009; 140: 191-6.

25. Kilic YA, Konan A, Kaynaroglu V. Resuscitation and monitoring in gastrointestinal bleeding. Eur J Trauma Emerg Surg 2011; 37: 329-37.

26. Riazi S, Karkouti K, Heggie J. Case report: management of lifethreatening oropharyngeal bleeding with recombinant factor VIIa. Can J Anesth 2006; 53: 881-4.

27. Hwang HD, Kim JW, Kim YS, Kang DH, Kwon TG. Angiographic embolization for hemorrhage control after dental implantation. J Korean Assoc Oral Maxillofac Surg 2013; 39: 27-30.

28. Iqbal IZ, Jones $G H$, Dawe $N$, et al. Intranasal packs and haemostatic agents for the management of adult epistaxis: systematic review. J Laryngol Otol 2017; 131: 1065-92.

29. Wall JJ, Tay KY. Postoperative tonsillectomy hemorrhage. Emerg Med Clin North Am 2018; 36: 415-26.

30. Hankerson MJ, Raffetto B, Mallon WK, Shoenberger JM. Nebulized tranexamic acid as a noninvasive therapy for cancerrelated hemoptysis. J Palliat Med 2015; 18: 1060-2.

31. Zahed R, Mousavi Jazayeri MH, Naderi A, Naderpour Z, Saeedi $M$. Topical tranexamic acid compared with anterior nasal packing for treatment of epistaxis in patients taking antiplatelet drugs: randomized controlled trial. Acad Emerg Med 2018; 25: 261-6.

32. Weingart SD, Trueger NS, Wong N, Scofi J, Singh N, Rudolph SS. Delayed sequence intubation: a prospective observational study. Ann Emerg Med 2015; 65: 349-55.

33. Nфrskov A, Wetterslev J, Rosenstock CV, et al. Effects of using the simplified airway risk index versus usual airway assessment on unanticipated difficult tracheal intubation - a cluster randomised trial with 64,273 participants. Br J Anaesth 2016; 116: 680-9.

34. Teoh WH, Kristensen MS. Prediction in airway management: what is worthwhile, what is a waste of time and what about the future? Br J Anaesth 2016; 117: 1-3.

35. Kristensen M. Predicting difficult intubation 2. Anaesthesia 2002; 57: 612; discussion 612-3

36. Navsa N, Tossel G, Boon JM. Dimensions of the neonatal cricothyroid membrane - how feasible is a surgical cricothyroidotomy? Paediatr Anaesth 2005; 15: 402-6.

37. Weiss M, Engelhardt T. Proposal for the management of the unexpected difficult pediatric airway. Paediatr Anaesth 2010; 20: 454-64.

38. Kristensen MS, Teoh WH, Baker PA. Percutaneous emergency airway access; prevention, preparation, technique and training. $\mathrm{Br}$ J Anaesth 2015; 114: 357-61.

39. Kristensen MS, Teoh WH, Rudolph SS. Ultrasonographic identification of the cricothyroid membrane: best evidence, techniques, and clinical impact. Br J Anaesth 2016; 117(Suppl 1): i39-48.

40. Oh H, Yoon S, Seo M, et al. Utility of the laryngeal handshake method for identifying the cricothyroid membrane. Acta Anaesthesiol Scand 2018; 62: 1223-8.
41. Stafrace S, Engelhardt T, Teoh WH, Kristensen MS. Essential ultrasound techniques of the pediatric airway. Paediatr Anaesth 2016; 26: 122-31.

42. Fichtner A, Vrtny $P$, Schaarschmidt $F$. Ultrasound-guided retrograde emergency intubation: life-saving management of a bleeding airway emergency with unclear anatomical situation (German). Anaesthesist 2015; 64: 948-52.

43. Mercer SJ, Lewis SE, Wilson SJ, Groom P, Mahoney PF. Creating airway management guidelines for casualties with penetrating airway injuries. J R Army Med Corps 2010; 156(4Suppl 1): 355-60.

44. Kovacs $G$, Sowers $N$. Airway management in trauma. Emerg Med Clin North Am 2018; 36: 61-84.

45. Vlatten A, Helm M. Management of a child with a history of difficult intubation and post-tonsillectomy bleed. In: Hung OR, Murphy MF, editors. Hung's Difficult and Failed Airway Management. 3rd ed. New York: McGraw-Hill Education; 2018. p. 530-4.

46. DuCanto J, Serrano KD, Thompson RJ. Novel airway training tool that simulates vomiting: suction-assisted laryngoscopy assisted decontamination (SALAD) system. West J Emerg Med 2017; 18: 117-20.

47. Christodoulou CC, Hung OR, Zhang J. Novisual intubation techniques. In: Hung OR, Murphy MF, editors. Hung's Difficult and Failed Airway Management. 3rd ed. New York: McGrawHill Education; 2018. p. 222-37.

48. Whitlock JE, Calder I. Transillumination in fibreoptic intubation. Anaesthesia 1987; 42: 570-1.

49. Sparrow K, Hung OR. Ankylosing spondylitis: intubation using a lightwand. In: Doyle DJ, Abdelmalak B, editors. Clinical Airway Management An Illustrated Case-Based Approach. Cambridge: Cambridge Medicine; 2017. p. 108-11.

50. Kristensen MS. Airwaymanagement.dk.: Retrograde intubation with the pulling-the-catheter-method in bloody, bleeding, patients with difficult airway. Available from URL: www. airwaymanagement.dk/retrograde (accessed (November, 2018)).

51. Weingarten TN, Bojanic K, Sprung J. Airway bleed following partial cordectomy. In: Doyle DJ, Abdelmalak B (Eds). Clinical Airway Management A Case-Based Approach: Cambridge Medicine; 2017: 214-6.

52. Preis CA, Hartmann T, Zimpfer $M$. Laryngeal mask airway facilitates awake fiberoptic intubation in a patient with severe oropharyngeal bleeding. Anesth Analg 1998; 87: 728-9.

53. Timmermann A, Russo $S G$, Rosenblatt $W H$, et al. Intubating laryngeal mask airway for difficult out-of-hospital airway management: a prospective evaluation. Br J Anaesth 2007; 99: 286-91.

54. Dalesio NM. Management of post-tonsillectomy hemorrhage. In: Berkow LC, Sakles JC, editors. Cases in Emergency Airway Management. Cambridge: Cambridge University Press; 2015. p. 184-9.

55. Jagannathan N, Wong DT. Successful tracheal intubation through an intubating laryngeal airway in pediatric patients with airway hemorrhage. J Emerg Med 2011; 41: 369-73.

56. Theiler L, Kleine-Brueggeney $M$, Urwyler $N$, Graf $T$, Luyet $C$, Greif $R$. Randomized clinical trial of the $\mathrm{i}-\mathrm{gel}^{\mathrm{TM}}$ and Magill tracheal tube or single-use ILMA ${ }^{\mathrm{TM}}$ and ILMA $^{\mathrm{TM}}$ tracheal tube for blind intubation in anaesthetized patients with a predicted difficult airway. Br J Anaesth 2011; 107: 243-50.

57. Kleine-Brueggeney $M$, Nicolet A, Nabecker $S$, et al. Blind intubation of anaesthetised children with supraglottic airway devices AmbuAura-i and Air-Q cannot be recommended: a randomised controlled trial. Eur J Anaesthesiol 2015; 32: 631-9.

58. Kleine-Brueggeney $M$, Theiler L, Urwyler $N$, Vogt A, Greif $R$. Randomized trial comparing the i-gel ${ }^{\mathrm{TM}}$ and Magill tracheal tube with the single-use ILMA ${ }^{\text {TM }}$ and ILMA $^{\text {TM }}$ tracheal tube for 
fibreoptic-guided intubation in anaesthetized patients with a predicted difficult airway. Br J Anaesth 2011; 107: 251-7.

59. Miner JR, Rubin J, Clark J, Reardon RF. Retrograde intubation with an extraglottic device in place. J Emerg Med 2015; 49: 8647.

60. Mabry RL, Kharod CU, Bennett BL. Awake cricothyrotomy: a novel approach to the surgical airway in the tactical setting. Wilderness Environ Med 2017; 28: S61-8.

61. Baker PA, O'Sullivan EP, Kristensen MS, Lockey D. The great airway debate: is the scalpel mightier than the cannula? $\mathrm{Br} \mathrm{J}$ Anaesth 2016; 117(Suppl 1): i17-9.

62. Wexler $S$, Hall $K$, Chin $R Y$, Prineas SN. Cannula cricothyroidotomy and rescue oxygenation with the Rapid$\mathrm{O} 2^{\mathrm{TM}}$ oxygen insufflation device in the management of a can't intubate/can't oxygenate scenario. Anaesth Intensive Care 2018; 46: $97-101$.

63. Fang CH, Friedman R, White PE, Mady LJ, Kalyoussef E. Emergent awake tracheostomy-the five-year experience at an urban tertiary care center. Laryngoscope 2015; 125: 2476-9.

64. Kristensen $M S, T e o h W H$. Front of neck: continued discovery of this anatomy essential for airway management. $\mathrm{Br} \mathrm{J}$ Anaesth 2018; 120: 895-8.

65. Abou-Madi MN, Trop D. Pulling versus guiding: a modification of retrograde guided intubation. Can J Anaesth 1989; 36: 336-9.

66. Vieira D, Lages $N$, Dias J, Maria L, Correia C. Ultrasoundguided retrograde intubation. Anaesthesia 2013; 68: 1075-6.

67. Hung OR. al-Qatari M. Light-guided retrograde intubation. Can J Anaesth 1997; 44: 877-82.

68. Ryu T, Kim DH, Byun SH. Fiberoptic bronchoscopic treatment of blood aspiration and use of sugammadex in a patient with epistaxis: a case report. Medicine (Baltimore) 2018; DOI: https:// doi.org/10.1097/MD.0000000000010428.

69. Kuriyama A, Umakoshi N, Sun R. Prophylactic corticosteroids for prevention of postextubation stridor and reintubation in adults: a systematic review and meta-analysis. Chest 2017; 151: 1002-10.

70. Andre N, Klopp-Dutote N, Biet-Hornstein A, Strunski V, Page C. Cardiovascular risk and severity factors in patients admitted to hospital for spontaneous epistaxis. Eur Ann Otorhinolaryngol Head Neck Dis 2018; 135: 119-22.

71. Jacobs IN, Cahill AM. Special considerations in vascular anomalies: airway management. Clin Plast Surg 2011; 38: 12131.

72. See A, Sudirman SR, Huang $X Y$. Spontaneous multilevel airway haemorrhage in acquired haemophilia A. Eur Arch Otorhinolaryngol 2017; 274: 2657-60.

73. Klauser R, Roggla G, Pidlich J, Leithner C, Frass M. Massive upper airway bleeding after thrombolytic therapy: successful airway management with the Combitube. Ann Emerg Med 1992; 21: 431-3.

74. Balaguer-Marti JC, Penarrocha-Oltra D, Balaguer-Martinez J, Penarrocha-Diago M. Immediate bleeding complications in dental implants: a systematic review. Med Oral Patol Oral Cir Bucal 2015; 20: e231-8.

75. Elsharydah A. The Laryngeal Mask Airway may help to protect the lungs and control bleeding in a patient with significant pharyngeal bleeding. J Clin Anesth 2008; 20: 155.

76. Inoue $S$, Fujimoto $Y$, Kawano $Y$, Furuya $H$. Difficult passage of the endotracheal tube and massive nasal bleeding during awake nasal fiberoptic intubation in a patient with airway obstruction caused by neck hematoma-a case report. Middle East J Anaesthesiol 2011; 21: 125-7.

77. Ali S, Athar M, Ahmed SM, Siddiqi OA, Badar A. A randomized control trial of awake oral to submental conversion versus asleep technique in maxillofacial trauma. Ann Maxillofac Surg 2017; 7: 202-6.
78. Jimenez-Zarazua O, Lopez-Garcia JA, Arce-Negrete LR, VelezRamirez LN, Casimiro-Guzman L, Mondragon JD. Alveolar hemorrhage associated with cocaine consumption. Heart Lung 2018; 47: 525-30.

79. Sahovaler A, Eibling DE, Bruni I, et al. Novel minimally invasive transoral surgery bleeding model implemented in a nationwide otolaryngology emergencies bootcamp. J Robot Surg 2019; DOI: https://doi.org/10.1007/s11701-019-00920-7.

80. El-Boghdadly K, Onwochei DN, Cuddihy J, Ahmad I. A prospective cohort study of awake fibreoptic intubation practice at a tertiary centre. Anaesthesia 2017; 72: 694-703.

81. Archan S, Gumpert $R$, Kugler B, Seibert FJ, Prause G. Cricothyroidotomy on the scene in a patient with severe facial trauma and difficult neck anatomy. Am J Emerg Med 2009; 27(133): e1-4.

82. Paul $C$, Sanader $S$, Wetch WA, Stangl R, Lechleuter A. Lifethreatening post-tonsillectomy hemorrhage including suggestions for a prehospital emergency care algorithm (German). Notfall Rettungsmed 2018; 21: 603-8.

83. Saladi L, Lvovsky D. Organized blood clot masquerading as endobronchial tumor: a review of management and recent advances. Respir Med Case Rep 2018; 24: 165-9.

84. Cogbill TH, Cothren CC, Ahearn MK, et al. Management of maxillofacial injuries with severe oronasal hemorrhage: a multicenter perspective. J Trauma 2008; 65: 994-9.

85. Rosenstock CV, Norskov AK, Wetterslev J, Lundstrom LH, Danish Anaesthesia Database. Emergency surgical airway management in Denmark: a cohort study of 452461 patients registered in the Danish Anaesthesia Database. Br J Anaesth 2016; 117: i75-82.

86. Waberski AT, Espinel AG, Reddy $S K$. Anesthesia safety in otolaryngology. Otolaryngol Clin North Am 2019; 52: 63-73.

87. Timmermann A. Retrograde intubation in an emergency situation - indication, technical performance, risks and pitfalls (German). Anasthesiol Intensivmed Notfallmed Schmerzther 2012; 47: 45863.

88. Weksler $N$, Klein $M$, Weksler $D$, et al. Retrograde tracheal intubation: beyond fibreoptic endotracheal intubation. Acta Anaesthesiol Scand 2004; 48: 412-6.

89. Dhara SS. Retrograde tracheal intubation. Anaesthesia 2009; 64: 1094-104.

90. Dong $Y, L i G, W u W$, Su $R$, Shao $Y$. Lightwand-guided nasotracheal intubation in oromaxillofacial surgery patients with anticipated difficult airways: a comparison with blind nasal intubation. Int J Oral Maxillofac Surg 2013; 42: 1049-53.

91. Hung OR, Pytka S, Morris I, Murphy M, Stewart RD. Lightwand intubation: II-clinical trial of a new lightwand for tracheal intubation in patients with difficult airways. Can J Anaesth 1995; 42: 826-30.

92. Weitzel N, Kendall J, Pons P. Blind nasotracheal intubation for patients with penetrating neck trauma. J Trauma 2004; 56: 1097 101.

93. Fiadjoe JE, Stricker $P$, Gurnaney $H$, et al. Ultrasound-guided tracheal intubation: a novel intubation technique. Anesthesiology 2012; 117: 1389-91.

94. Moustafa MA, Arida EA, Zanaty OM, El-Tamboly SF. Endotracheal intubation: ultrasound-guided versus fiberscope in patients with cervical spine immobilization. J Anesth 2017; 31: 846-51.

95. Bhagwat AG, Saxena KN, Dua $K$, Sharma R, Jain A. A novel use of esophageal tracheal airway: the control of torrential oral bleeding. Minerva Anestesiol 2008; 74: 675-7.

96. de Paiva Fagundes AA, Jr Chaves RB, dos Santos AR, de Oliveira $H A$, Paschoal $M H$. Massive hemoptysis successfully treated with extracorporeal membrane oxygenation and endobronchial 
thrombolysis (Portuguese). Rev Bras Ter Intensiva 2018; 30: 11620.

97. Haijima $N$, Kawahito $K$, Abe $T$, et al. Treatment of a massive tracheal bleeding with percutaneous cardiopulmonary support (Japanese). Kyobu Geka 2008; 61: 1092-5.
Publisher's Note Springer Nature remains neutral with regard to jurisdictional claims in published maps and institutional affiliations. 